\title{
Validation of the Trail Making Test $B$ for the Cognitive Assessment of Patients with Cancer in Palliative Care*
}

\author{
Juliano dos Santos ${ }^{1,2 \#, ~ C i b e l e ~ A n d r u c i o l i ~ d e ~ M a t t o s ~ P i m e n t a ㄹ ㅡ, ~ G e a n a ~ P a u l a ~ K u r i t a ~}{ }^{3}$, \\ Patrícia Emília Braga ${ }^{2}$, Per Sjøgren ${ }^{3}$ \\ ${ }^{1}$ National Cancer Institute-HC III, Rio de Janeiro, Brazil \\ ${ }^{2}$ Department of Medical Surgical Nursing, School of Nursing, University of Sao Paulo, São Paulo, Brazil \\ ${ }^{3}$ Rigshospitalet, Section of Palliative Medicine, Multidisciplinary Pain Centre, Copenhagen, Denmark \\ Email: "jinsantos@yahoo.com.br
}

Received 16 May 2014; revised 24 June 2014; accepted 5 July 2014

Copyright (C) 2014 by authors and Scientific Research Publishing Inc.

This work is licensed under the Creative Commons Attribution International License (CC BY). http://creativecommons.org/licenses/by/4.0/

(c) (i) Open Access

\section{Abstract}

Introduction: Cognitive impairment is common in patients with cancer; however, studies examining the adaptation and validation of instruments for use in patients with cancer are scarce. Purpose: The purpose of this study was to validate the Trail Making Test B (TMT-B) for use in patients with cancer. Methods: Ninety-four outpatients receiving palliative treatment and 39 healthy companions were assessed. Patients were tested with the TMT-B and answered questions regarding the presence and intensity of pain, fatigue, quality of sleep, anxiety, and depression, at two time points with a 7-day inter-assessment interval. Results: The instrument discriminated between patients, who were slower, and healthy companions with respect to the time required to complete the test, but not in terms of the number of errors. The test was stable for the healthy companions across the two assessments in terms of time to complete the TMT-B and the number of errors; for patients, the instrument was stable only for the number of errors. Performance on the TMT-B did not correlate with pain, fatigue, depression, anxiety, or sensation of rest. Conclusions: TMT-B cannot be considered fully validated. Further studies incorporating and comparing other instruments evaluating executive function and mental flexibility are needed.

\section{Keywords}

Cognition, Executive Function, Hospice Care, Neoplasms, Neuropsychological Tests, Validation Studies

\footnotetext{
“Masters thesis presented to the Graduate Program in Adult Health Nursing at the University of São Paulo’s School of Nursing.

"Corresponding author.
} 


\section{Introduction}

Cognitive impairment is common in patients with cancer (7.4\% - 90.5\%), especially in the final stages of the disease [1] [2]; delirium and dementia are prevalent, with estimates of their incidence rates being in the range of $28 \%$ - $88 \%$ for the former and $11 \%$ for the latter [3]-[5]. However, small and subtle cognitive changes in particular cognitive domains - such as attention, memory, organization, reaction time-are frequent and can impair patient's day-to-day functionality, including treatment related decisions. There are few studies regarding the prevalence of cognitive impairment in patients with cancer in palliative care treatment. A multinational study with 1915 patients with advanced cancer reported that 32.9\% of these patients had low scores $(<27)$ on Minimental State Examination [6]. Two studies that analyzed the mental flexibility and/or executive function of patients with cancer receiving palliative care reported changes in $28 \%$ [7] and $44 \%$ of this population, respectively [8].

In Brazil, this issue has received little attention, and it is believed that, just as in other countries, these changes frequently pass unnoticed and are not systematically assessed. The shortage of adequate instruments to perform cognitive evaluation in this population further contributes to the failure of building up knowledge about this issue.

There exist many tests and questionnaires that evaluate one or several aspects of mental function, and there also exist neuropsychology compendia designed to bring together information from several tests [9]. However, studies examining the adaptation and validation of these instruments for use in patients with cancer are scarce [10], and there is very limited information about the clinical validity and reliability of these instruments in patients with cancer receiving palliative care [10]. There exist studies in healthy subjects which have analyzed the psychometric properties of the Trail Making Test (TMT) and demonstrated satisfactory reliability and valididity of the test [11]-[13]. However, to our knowledge, there are no studies which have analyzed the validity of the test in patients with advanced cancer. This population is exposed to different factors related to disease and treatment and may have a different cognitive performance when compared to healthy people. Therefore, the validation of this instrument to patients in palliative cancer care is necessary.

The TMT-B evaluates components of executive function and mental flexibility [14], allowing for a rapid, wide-ranging and efficient evaluation of cognitive function. It has commonly been used to assess functional brain damage [14] and has been implemented in clinical studies involving patients with cancer receiving palliative care [8] [15] [16]; however, it has yet to be validated for use in Brazilian patients with advanced cancer. Therefore this study's objective was to test the validity of the Trail Making Test - B (TMT-B) for use in patients with cancer in palliative care.

\section{Methods}

\subsection{Sample, Location, and Study Period}

A methodological study to test the validity of the TMT-B was conducted with a convenient sample of 133 individuals, including 94 patients with cancer receiving palliative care and 39 patient companions (informal caregivers) serving as a control group. Patients in palliative care were defined as those receiving palliative treatment, including chemotherapy and/or radiotherapy and/or hormone therapy, confirmed by the medical records. The inclusion criteria and data collection procedures are summarized in Figure 1. The data were collected at the chemotherapy clinic of the Cancer Institute of the State of São Paulo (ICESP) between October 2010 and February 2011. The Research Ethics Committees of the School of Nursing at the University of São Paulo and of the ICESP approved the study and all participants provided informed consent.

\subsection{Assessment}

Socio-demographic characteristics, quality of sleep, presence and intensity of pain, fatigue, cognitive function, anxiety, depression, disease characteristics, current anticancer treatment regimens, and clinical variables were assessed in all subjects. Patients and volunteers were re-assessed within a 7-day interval and instruments applied in both assessments can be seen in Figure 1.

Functional capacity was evaluated using the Karnofsky Performance Status scale (KPS) [17]. Its score varies from $100 \%$, which indicates normal health condition, to $0 \%$, which indicates death.

Regarding assessment of quality of sleep, the subjects were asked if they wake up feeling tired and how rested 


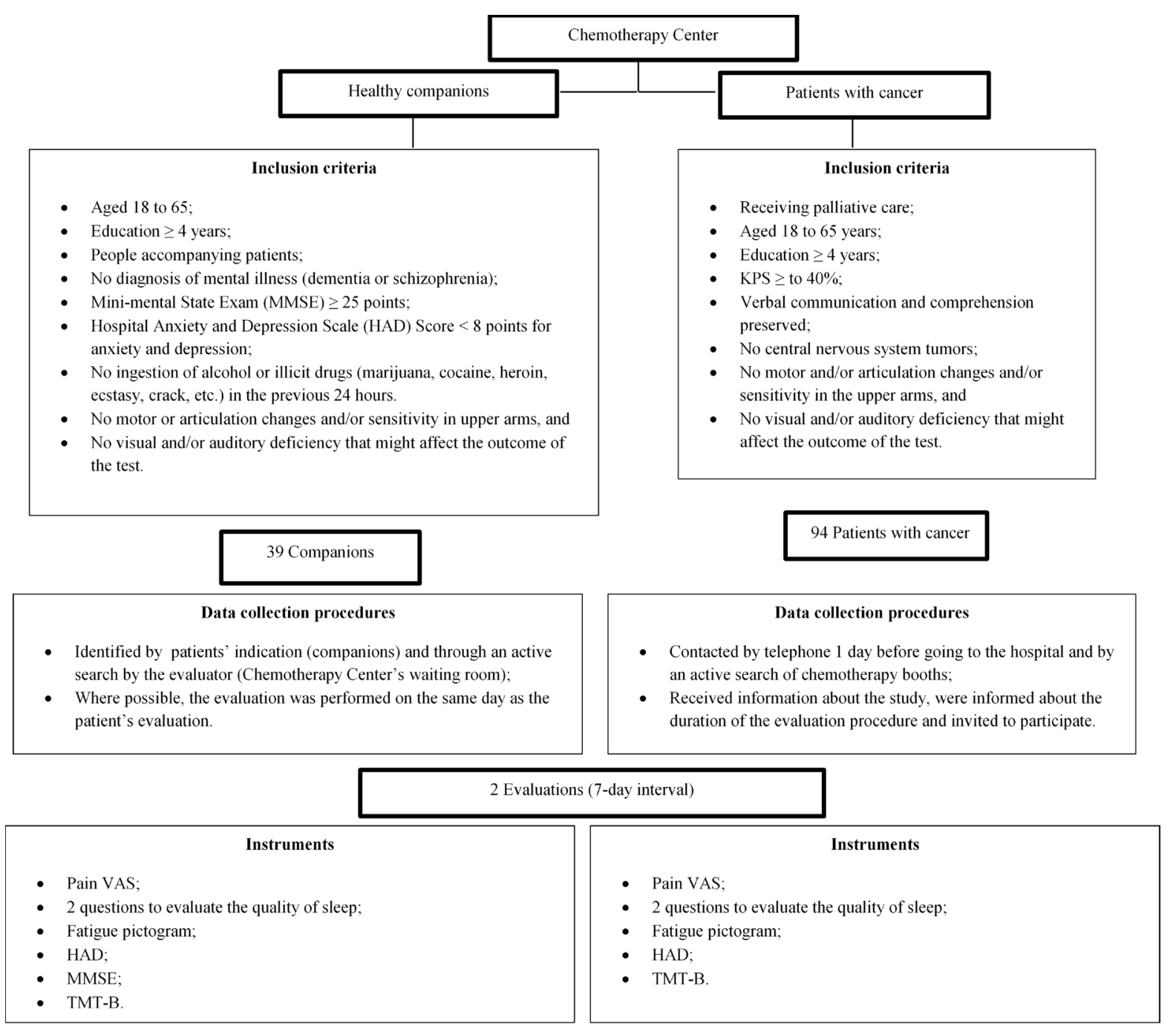

Figure 1. Inclusion criteria and data collection procedures.

they felt on a visual numerical rating scale from 0 to 10, in which 0 represented "no rest" and 10 represented "being fully rested".

The presence and intensity of pain at the time of interview was assessed using a numerical rating scale, where 0 represented "no pain" and 10 represented "worst pain imaginable" [18].

We evaluated fatigue intensity and the impact of fatigue on daily activities over the previous week using the Brazilian version of the Fatigue Pictogram, which previously has been validated in patients with cancer and reflect the intensity and impact of the perceived fatigue [19]. Scores range from 1 to 5 for both the dimensions (intensity and impact on daily activities).

The TMT, which is used to evaluate executive function and mental flexibility, involves two parts: the Trail Making Test A (TMT-A), consisting of numbers, and the TMT-B, consisting of numbers and letters.

In the TMT-A, the subject uses a pencil or pen to draw a line connecting a series of numbers in increasing order (from 1 to 25 ) shown in random circles, in a numerical sequence. In the TMT-B, which was applied here, the subject must link numbers (from 1 to 13 ) to letters (from A to L) inside circles in alternating sequences, in increasing order [9]. The TMT-A and TMT-B assess similar domains; however, the TMT-B is more demanding and requires more cognitive flexibility [20].

The criteria used to grade the TMT-B results were the time (in seconds) needed to complete the test correctly and the number of mistakes in the sequence. Longer time needed to complete and higher number of mistakes indicated worse performance, in other words, higher scores indicate worse performance. The version used in this 
study [21] also involved a small change of the instrument: We suppressed the letter K, since, in the Portuguese language, it is only used for abbreviations and for foreign words and their derivatives. In the final instrument version letters were from $\mathrm{A}$ to $\mathrm{M}$ and numbers from 1 to 13 .

We evaluated anxiety and depression based on a version of the Hospital Anxiety and Depression Scale (HAD) validated for Brazilian culture [22].

It consists in two sub-scales and the maximum score for each scale is 21 . The recommended cut-off points for each sub-scale are: no anxiety or depression (0 - 7); possible anxiety or depression (8 - 10), and probable anxiety or depression $(\geq 11)$ [23].

We used the Mini-mental State Examination (MMSE) to confirm that control subjects did not have cognitive impairment. This instrument consists of questions to assess several cognitive domains. In this study, we adopted an inclusion cut-off score of $\geq 25$ points for individuals with at least 4 years of education [24].

\subsection{Data Analysis and Procedures for Analysis of Psychometric Properties}

We used the STATA statistical program, version 11, to analyze the data. A significance level of 5\% was adopted for all tests. To our knowledge no similar instrument is validated in Brazilian cancer patients. Therefore, we performed the techniques described below to analyse TMT-B.

Convergent/divergent validity was evaluated by assessing correlations between TMT-B scores and the variables anxiety, depression, fatigue, pain, and the quality of the previous night's sleep. Our hypotheses were that (1) a higher intensity of pain, fatigue, and anxiety/depression would be associated with higher TMT-B scores and (2) a better night's sleep would be associated with lower TMT-B scores. After verifying non-normality with the Shapiro Wilk test, Spearman's non-parametric correlation test was used to assess whether there were correlations between scores for pain, fatigue, anxiety, depression, and quality of sleep.

Discriminative validity was evaluated by comparing mean TMT-B scores for patients and healthy individuals. Our hypothesis was that the healthy companions would have a lower TMT-B score than the patients with cancer.

Reliability was evaluated by analyzing the stability of the TMT-B. We applied the TMT-B twice to the patients and the companions, respectively. The mean times and error number in the first and second evaluations were registered. Our hypothesis was that the results of the two evaluations would be similar.

\section{Results}

\subsection{Characteristics of the Sample and Clinical Variables}

Ninety-four patients and 39 companions were assessed in the first evaluation. In the second evaluation, 47 patients and 18 companions were retested. The number of participants on the second assessment was lower because some forgot the scheduled appointment, considered the distance between home and hospital too long, patients had worsened general condition and decreased functional capacity.

The patients were men $(52.1 \%)$, mean age $53.7(\mathrm{SD}=8.0)$, living with a partner $(62 \%)$; $47.9 \%$ of the patients had elementary or middle school level educations (4 - 8 years of schooling). Colon cancer was the most common diagnosis, followed by breast and rectal cancers. All the patients had metastasis, and a substantial number ( $\mathrm{n}=$ 67, 71.3\%) had one site of metastasis usually in the liver or the lungs. Nearly all the patients (97.9\%) were receiving chemotherapy and $61.7 \%$ had high KPS scores between $80 \%$ and $100 \%$ (Table 1).

The healthy companions were predominantly women, mean age was $46.9(\mathrm{SD}=15.0)$, living with a partner and with 9 to 11 years of schooling (Table 1).

Most of the patients (76.6\% at the $1^{\text {st }}$ evaluation and $69.0 \%$ at the $2^{\text {nd }}$ evaluation) and companions (82\% at the $1^{\text {st }}$ evaluation and $100 \%$ at the $2^{\text {nd }}$ evaluation) did not have pain. The majority of patients reported feeling rested during both interviews (74.5\% at the first evaluation and $65.5 \%$ at the second evaluation). With regard to fatigue, at the first evaluation, we noted that the averages for fatigue intensity and the impact of fatigue on day-to-day activities were $2.8(\mathrm{SD}=1.0)$ and $2.6(\mathrm{SD}=1.4)$, respectively. At the second evaluation, these averages were 2.7 ( $\mathrm{SD}=1.0$ ) and 2.7 ( $\mathrm{SD}=1.4$ ), respectively. Therefore, the patients did not report being very tired, and the impact of fatigue on their daily activities was limited. HAD data indicated that the patients had limited anxiety $\left(1^{\text {st }}\right.$ evaluation: mean $=6.5, \mathrm{SD}=4.4 ; 2^{\text {nd }}$ evaluation: mean $\left.=6.9, \mathrm{SD}=4.5\right)$ and $/$ or depression $\left(1^{\text {st }}\right.$ evaluation: mean $=5.9, \mathrm{SD}=3.9 ; 2^{\text {nd }}$ evaluation: mean $=6.4, \mathrm{SD}=4.1$ ) at the two evaluations.

The vast majority of the companions did not have pain (82\% at the 1 st evaluation and $100 \%$ at the 2nd evaluation) and felt rested (64.1\% and $90.9 \%$, respectively). 
Table 1. Sample’s sociodemographic characteristics and disease information.

\begin{tabular}{|c|c|c|c|}
\hline Variable & Patients $(n=94)$ & Companions $(n=39)$ & $p$ value \\
\hline Sex n (\%) & & & 0.002 \\
\hline Male & $49(52.1)$ & $9(23.1)$ & \\
\hline Female & $45(47.9)$ & $30(76.9)$ & \\
\hline \multicolumn{4}{|l|}{ Age, Years n (\%) } \\
\hline$<60$ & $73(76.3)$ & $31(79.5)$ & \multirow{2}{*}{0.694} \\
\hline$\geq 60$ & $22(23.7)$ & $8(20.5)$ & \\
\hline Mean (SD) Median (Range) & $\begin{array}{c}53.7(8.0) \\
55.2(29.4-65.7)\end{array}$ & $\begin{array}{c}46.9(15.0) \\
50.1(18.4-67.9)\end{array}$ & $0.043^{\mathrm{a}}$ \\
\hline \multicolumn{4}{|l|}{ Cohabiting partner n (\%) } \\
\hline Yes & $57(62.0)$ & $27(69.2)$ & \multirow[t]{2}{*}{0.427} \\
\hline No & $12(38.0)$ & $12(30.8)$ & \\
\hline \multicolumn{4}{|l|}{ Years of school n (\%) } \\
\hline 4 to 8 & 45 (47.9) & $12(30.8)$ & \multirow{4}{*}{0.157} \\
\hline 9 to 11 & 25 (26.6) & $13(33.3)$ & \\
\hline 12 to 17 & $17(18.1)$ & 7 (17.9) & \\
\hline$\geq 18$ & $7(7.4)$ & 7 (17.9) & \\
\hline $\begin{array}{c}\text { Mean (SD) } \\
\text { Median (Range) }\end{array}$ & $\begin{array}{c}10.0(4.7) \\
9.5(4-29)\end{array}$ & $\begin{array}{c}11.5(5.3) \\
11.0(4-27)\end{array}$ & $0.115^{\mathrm{a}}$ \\
\hline Cancer Type n (\%) & & - & \\
\hline Lung & $5(5.3)$ & - & \\
\hline Breast & 15 (15.9) & - & \\
\hline Pancreatic & $6(6.4)$ & - & \\
\hline Colorectal & $45(47.8)$ & - & \\
\hline Stomach & $8(8.5)$ & - & \\
\hline Bladder & $4(4.2)$ & - & \\
\hline Other & $10(11.9)$ & & \\
\hline Metastasis number $n=89(\%)$ & & - & \\
\hline 1 & $67(75.3)$ & - & \\
\hline 2 & 15 (16.9) & - & \\
\hline 3 or 4 & $7(7.8)$ & & \\
\hline Metastasis $n=89^{\mathrm{b}}(\%)$ & & - & \\
\hline Liver & $43(48.3)$ & - & \\
\hline Lung & $20(22.5)$ & - & \\
\hline Bone & $11(12.4)$ & - & \\
\hline Peritoneum & $8(9.0)$ & - & \\
\hline Ovarian & $2(2.2)$ & & \\
\hline Other & $19(21.3)$ & - & \\
\hline Unknown & $16(18.0)$ & & \\
\hline Present anticancer treatment $(n=94)$ & & - & \\
\hline No treatment & $2(2.2)$ & - & \\
\hline Receiving treatment $(n=92)$ & $92(97.9)$ & - & \\
\hline Chemotherapy & $90(95.7)$ & - & \\
\hline Chemo and radiotherapy or hormone & $2(2.2)$ & & \\
\hline Karnofsky performance status $(\mathrm{n}=68)$ & & - & \\
\hline $100 \%-80 \%$ & $58(85.3)$ & - & \\
\hline $70 \%$ or less & $10(11.2)$ & & \\
\hline
\end{tabular}

${ }^{\mathrm{a}}$ Mann-Whitney test; ${ }^{\mathrm{b}}$ some patients had more than one site of metastase. 
Their mean score for fatigue intensity was $2.5(\mathrm{SD}=1.1)$ at the first evaluation and $2.0(\mathrm{SD}=0.6)$ at the second evaluation, indicating low intensity of fatigue. The mean scores for the impact of fatigue were 1.7 ( $\mathrm{SD}=$ $1.0)$ and $1.5(\mathrm{SD}=0.9$ ) respectively, indicating little impact of fatigue (Table 1$)$. At the first evaluation, the companion group had a mean anxiety score of $6.5(\mathrm{SD}=2.6)$ and a mean depression score of $4.9(\mathrm{SD}=3.1)$. At the second evaluation, these averages were $4.9(\mathrm{SD}=3.1)$ and $4.4(\mathrm{SD}=3.0)$, respectively.

Symptoms did not differ between first and second evaluations among patients and companions.

\subsection{Psychometric Properties of the TMT-B}

Convergent/divergent validity. We did not observe statistically significant correlations between TMT-B outcome and intensity of anxiety, depression, fatigue, pain, and intensity of rest attributed to the previous night's sleep (Table 2).

With respect to the number of errors, we observed a negative correlation between pain intensity and TMT-B performance at the second evaluation (Table 2).

Discriminative validity. The companions did complete the TMT-B in less time than the patients at both evaluations (Table 3); however, the two groups had a similar number of errors (Table 3).

Reliability. We evaluated the TMT-B's reliability through a test-retest stability analysis. The companions used a similar amount of time to complete the TMT-B at the test and re-test, while the patients required more time to complete the test than the re-test (Table 4). With respect to the number of errors, both the patients and the companions performed similarly on the test and re-test (Table 4).

\section{Discussion}

Normative studies of the TMT have examined different populations, including both patients [8] [15] [16] and healthy individuals [11]-[13] [20] [25] [26]. However, few have evaluated the test's psychometric properties [11]-[13], and we are unaware of any studies validating the TMT-B for use in patients with cancer. This study tested the TMT-B's validity by analyzing convergent/divergent validity and discriminative validity.

Table 2. Correlation between the number of errors made by patients completing the TMT-B and anxiety, depression, fatigue, pain, and the rest attributed to the previous night's sleep.

\begin{tabular}{|c|c|c|c|c|c|}
\hline \multirow{2}{*}{ Variable } & \multirow{2}{*}{$\mathbf{N}^{\mathrm{a}}$} & \multicolumn{2}{|c|}{ Time to complete } & \multicolumn{2}{|c|}{ Number of errors } \\
\hline & & $\mathbf{r}_{\text {Spearman }}$ & $p$ value & $\mathbf{r}_{\text {Spearman }}$ & p value \\
\hline \multicolumn{6}{|l|}{$1^{\text {st }}$ Evaluation } \\
\hline Anxiety & 94 & 0.114 & 0.273 & -0.034 & 0.745 \\
\hline Depression & 94 & 0.047 & 0.650 & -0.056 & 0.594 \\
\hline Intensity of fatigue & 94 & 0.077 & 0.460 & -0.030 & 0.772 \\
\hline Impact of fatigue & 94 & 0.109 & 0.297 & -0.089 & 0.396 \\
\hline Pain & 93 & 0.132 & 0.206 & -0.105 & 0.318 \\
\hline Woke up rested & 94 & 0.008 & 0.940 & 0.075 & 0.473 \\
\hline \multicolumn{6}{|l|}{$2^{\text {nd }}$ Evaluation } \\
\hline Anxiety & 29 & 0.113 & 0.560 & -0.242 & 0.206 \\
\hline Depression & 29 & 0.071 & 0.715 & -0.090 & 0.642 \\
\hline Intensity of fatigue & 28 & 0.151 & 0.445 & -0.206 & 0.292 \\
\hline Impact of fatigue & 28 & 0.242 & 0.215 & -0.039 & 0.844 \\
\hline Pain & 29 & -0.047 & 0.810 & -0.435 & 0.018 \\
\hline Woke up rested & 29 & 0.068 & 0.725 & 0.268 & 0.160 \\
\hline
\end{tabular}

${ }^{\mathrm{a}}$ Patients that did not present the symptom were excluded from analyses. 
Table 3. Comparison of the time needed by the patients and the companions to complete the test and the number of errors made at the $1^{\text {st }}$ and $2^{\text {nd }}$ evaluations of the TMT-B (Discriminant Validity).

\begin{tabular}{|c|c|c|c|c|c|c|c|}
\hline TMT-B & $\mathbf{n}^{0}$ & Mean & SD & Median & Minimum & Maximum & $p$ value \\
\hline \multicolumn{8}{|l|}{ Time } \\
\hline $1^{\text {st }}$ Evaluation & & & & & & & $0.014^{\mathrm{a}}$ \\
\hline Companions & 39 & 127.3 & 83.3 & 87 & 46 & 345 & \\
\hline Patients & 94 & 147.5 & 71.6 & 129 & 47 & 443 & \\
\hline $2^{\text {nd }}$ Evaluation & & & & & & & $0.035^{\mathrm{a}}$ \\
\hline Companions & $18^{\mathrm{b}}$ & 110.7 & 86.3 & 83.5 & 41 & 370 & \\
\hline Patients & 47 & 132.0 & 68.2 & 109 & 55 & 362 & \\
\hline \multicolumn{8}{|l|}{ Errors } \\
\hline $1^{\text {st }}$ Evaluation & & & & & & & 0.914 \\
\hline Companions & 39 & 0.9 & 1.2 & 1 & 0 & 4 & \\
\hline Patients & 94 & 1.0 & 1.3 & 1 & 0 & 6 & \\
\hline $2^{\text {nd }}$ Evaluation & & & & & & & 0.620 \\
\hline Companions & $19^{\mathrm{b}}$ & 0.6 & 0.8 & 0 & 0 & 3 & \\
\hline Patients & 47 & 0.8 & 1.0 & 0 & 0 & 3 & \\
\hline
\end{tabular}

${ }^{\mathrm{a}}$ Mann-Whitney test; ${ }^{\mathrm{b}}$ One patient made mistakes and gave up completing the test.

Table 4. Descriptive statistics for the time consumed by the patients and the companions to complete the test and the number of errors made at the $1^{\text {st }}$ and $2^{\text {nd }}$ evaluations (Reliability).

\begin{tabular}{|c|c|c|c|c|c|c|c|}
\hline TMT- B & $n^{0}$ & Mean & SD & Median & Minimum & Maximum & p value \\
\hline \multicolumn{8}{|l|}{ Time } \\
\hline Companions & & & & & & & $0.071^{\mathrm{a}}$ \\
\hline $1^{\text {st }}$ Evaluation & $18^{* *}$ & 120.8 & 77.3 & 84.5 & 46 & 294 & \\
\hline $2^{\text {nd }}$ Evaluation & $18^{* *}$ & 110.7 & 86.3 & 83.5 & 41 & 370 & \\
\hline Patients & & & & & & & $0.039^{a}$ \\
\hline $1^{\text {st }}$ Evaluation & 47 & 139.0 & 56.0 & 128 & 47 & 306 & \\
\hline $2^{\text {nd }}$ Evaluation & 47 & 132.0 & 68.2 & 109 & 55 & 362 & \\
\hline \multicolumn{8}{|l|}{ Errors } \\
\hline Companions & & & & & & & 0.352 \\
\hline $1^{\text {st }}$ Evaluation & $19^{\mathrm{b}}$ & 0.9 & 1.0 & 1 & 0 & 4 & \\
\hline $2^{\text {nd }}$ Evaluation & $19^{\mathrm{b}}$ & 0.6 & 0.8 & 0 & 0 & 3 & \\
\hline Patients & & & & & & & 0.913 \\
\hline $1^{\text {st }}$ Evaluation & 47 & 0.9 & 1.4 & 0 & 0 & 6 & \\
\hline $2^{\text {nd }}$ Evaluation & 47 & 0.8 & 1.0 & 0 & 0 & 3 & \\
\hline
\end{tabular}

${ }^{\mathrm{a}}$ Wilcoxon's test; ${ }^{\mathrm{b}}$ One patient made mistakes and gave up completing the test.

We expected that individuals who were experiencing pain, fatigue, anxiety, and depression would not perform as well on the test as their healthy companions, and that restful sleep on the previous night would be associated with better performance on the test. We did not observe a correlation between the time needed to perform the TMT-B and the selected variables. For number of errors, we did observe a negative correlation between TMT-B and pain scores. 
We were surprised by these findings because, although there is no consensus, some studies involving a small number of patients found a relationship between these symptoms and cognitive performance on other cognitive tests than the TMT-B [15] [27] [28].

Although not without limitations, these findings support the hypotheses that TMT-B performance may be influenced by the variables we selected to analyze convergent/divergent validity (Table 2). However, maybe the relationships are not significant in the absence of severe symptoms.

One possible explanation for why we did not find correlations between test performance and the other variables may be an inadequacy in our hypotheses. That is, fatigue, pain, sleep changes, anxiety, and depression were not constructed in relation to the TMT-B.

However, the pathophysiology and clinical manifestation of these symptoms would support the notion that individuals who are depressed, anxious, fatigued, and/or in pain should have impaired executive function and mental flexibility. It may be that the symptoms of the patients in our study cohort were, for the most part, too mild in intensity to significantly affect the variables. The majority of the patients had scores indicative of mild pain and mild fatigue. Likewise, the average scores for anxiety and depression did not indicate anxiousness or depression in our patient group (Table 2).

Another explanation could be that the uncorrelated variables lacked relevance or that the instruments used to measure them lacked sensitivity and accuracy. However, it should be noted that all of the instruments used were validated and or previously used in patients with cancer [18] [19] [22] [23]. Although this study's sample seems to be similar to those of other studies which have successfully used these instruments, it is possible that there may have been differences that are not apparent.

The negative correlation between the number of errors and pain intensity (Table 1) was surprising since pain is thought to interfere with attention [29] [30].

A Brazilian study comparing the cognitive function of patients with cancer using opioids for pain versus those not using opioids showed a negative correlation between pain intensity and performance on the MMSE and the Brief Cognitive Screening Battery, but not between pain intensity and TMT performance [15].

Our discriminative validity analysis showed that the TMT-B was able to discriminate between the two groupspatients and companions - with respect to the time needed to perform the test, both on the first and second evaluations, but not in terms of the number of errors made (Table 3 and Table 4). A former study analyzing the validity of the TMT-B in individuals with head trauma and healthy volunteers yielded similar results [31]. They observed a difference between those with head trauma and the control group in terms of the time needed to perform the test, but not in terms of the number of errors made [31].

Completing the TMT-B involves psychomotor speed, simple visual verification, and the ability to perform two differently directed activities at the same time in a not very demanding task. Therefore, it may be difficult to capture errors in people who do not have pronounced cognitive deficits. In the TMT-B, subjects must remember an alphabetical sequence in addition to a numerical sequence. Thus, the fact that the average level of education was similar between the patients (10 years) and their companions (11.5) helps justify their similar performance on the TMT-B (Table 1). In addition, it may be likely that patients were able to minimize errors by spending more time on completing the test.

We are not aware of former studies in patients with cancer that used the number of errors made on the TMT-B as a performance criterion. A study performed on healthy elderly people, some with depression, and others with schizophrenics, found that only the schizophrenics had an increased number of errors [32]. Another study did find a difference between healthy controls, people with mild cognitive impairment, and Alzheimer patients in terms of the number of errors made on the TMT-B. People with Alzheimer's disease had worse performance [33].

In the test-retest analysis, we did not observe a significant difference between the time needed to complete the test regarding the companions' first and second performance; however, the times to complete the two tests did differ regarding the patients performance (they were faster on the second assessment) (Table 4). Meanwhile, the number of errors made in executing the test did not vary significantly between the evaluations for either group, showing that the instrument was stable with respect to the number of errors in both groups (Table 4). To elucidate whether the TMT-B's stability or instability can be explained by changes in the variables of pain, fatigue, quality of sleep, anxiety, and/or depression, we compared these variables between the evaluations (Table 2). Between the first and second evaluations, we did not observe differences between the patients' median scores for any of these variables, though the patients' TMT-B scores differed between the evaluations. 
This dissociation indicates that the change in TMT-B performance was not related to these variables. Interestingly, TMT-B performance remained stable in the companion group, while the variable of anxiety showed a trend of reduction between the first and second evaluations, indicating that the test may not be affected by anxiety level (Table 2).

Given that test was repeated with a 7-day interval and the patients could have their health condition changed and they were in treatment-receiving chemotherapy and other medications, which might affect their clinical condition, it is an open question whether the methods were appropriate to investigate the test's stability in the patients group. . Studies performed in undergraduates [11] and healthy individuals have shown that the TMT-B is stable and reliable with the tests repeated over a 1-month interval, both for the time needed to perform the test and for the number of errors made [12] [13]. For our study, we choose to perform a test-retest stability analysis in patients due to our interest in evaluating the utility of the test in patients with cancer receiving palliative care. However, this study presented an important limitation that may be the reason why the reliability of the instruments has not been reconfirmed for this population. It is an unanswered question whether the methods were an adequate to investigate the test's stability in the patients group (long interval between assessments). Most likely the companions were more stable and, therefore, more suitable for this analysis. This assertion is supported by our findings.

This study, which was the first to evaluate the psychometric properties of the TMT-B in patients with cancer receiving palliative care, showed positive and negative aspects in terms of the instrument's validity and reliability. The instrument discriminated between patients with cancer and healthy age- and educationally matched individuals, in terms of time needed to complete the test. Further, TMT-B was stable across tests for the companion group in terms of time needed to complete the test and number of errors. The instrument was not stable in the patient group with respect to the time needed to perform the test. Meanwhile, the convergent/divergent validity was unsatisfactory for the two study groups as we did not observe a correlation between the TMT-B performance parameters studied and the variables of fatigue, quality of sleep, anxiety, and depression. In conclusion, the TMT-B failed in some of the validation steps in this sample of patients with cancer in palliative care. It should be considered as a test that requires further validation analyses and may be a valuable supplement to other neuropsychological tests. Futures studies should address the issues observed in this work and compare patients in different situations which involve risk factors for cognitive impairment related to disease and treatment.

\section{Summary}

In this sample TMT-B passed in some, but not in all the validation tests and a strong discussion gave us insights about the challenges of these results.

\section{Acknowledgments}

The authors thank the Agency for the Support and Development of Graduate Education (Coordenação de Aperfeiçoamento de Pessoal de Nível Superior, CAPES) for financing this study. We would also like to thank Professor Lona Christrup of the Department of Drug Design and Pharmacology, Faculty of Health and Medical Sciences University of Copenhagen (Denmark) for providing the cognitive test.

\section{References}

[1] Bruera, E., Miller, L., McCallion, J., Macmillan, K., Krefting, L. and Hanson, J. (1992) Cognitive Failure in Patients with Terminal Cancer: A Prospective Study. Journal of Pain and Symptom Management, 7, 192-195. http://dx.doi.org/10.1016/0885-3924(92)90074-R

[2] Brant, J.M. (2010) Palliative Care for Adults across the Cancer Trajectory: From Diagnosis to End of Life. Seminars in Oncology Nursing, 26, 222-230. http://dx.doi.org/10.1016/j.soncn.2010.08.002

[3] Centeno, C., Sanz, A. and Bruera, E. (2004) Delirium in Advanced Cancer Patients. Palliative Medicine, 18, $184-194$. http://dx.doi.org/10.1191/0269216304pm879oa

[4] Irwin, S.A., Zurhellen, C.H., Diamond, L.C., Dunn, L.B., Palmer, B.W., Jeste, D.V. and Twamley, E.W. (2008) Unrecognised Cognitive Impairment in Hospice Patients: A Pilot Study. Palliative medicine, 22, 842-847. http://dx.doi.org/10.1177/0269216308096907

[5] Leonard, M., Agar, M., Mason, C. and Lawlor, P. (2008) Delirium Issues in Palliative Care Settings. Journal of Psychosomatic Research, 65, 289-298. http://dx.doi.org/10.1016/j.jpsychores.2008.05.018 
[6] Kurita, G.P., Sjøgren, P., Ekholm, O., Kaasa, S., Loge, J.H., Poviloniene, I. and Klepstad, P. (2011) Prevalence and Predictors of Cognitive Dysfunction in Opioid-Treated Patients with Cancer: A Multinational Study. Journal of Clinical Oncology, 29, 1297-303. http://dx.doi.org/10.1200/JCO.2010.32.6884

[7] Mehta, M.P., Shapiro, W.R., Glantz, M.J., Patchell, R.A., Weitzner, M.A., Meyers, C.A. and Renschler, M.F. (2002) Lead-In Phase to Randomized Trial of Motexafin gadolinium and Whole-Brain Radiation for Patients with Brain Metastases: Centralized Assessment of Magnetic Resonance Imaging, Neurocognitive, and Neurologic end Points. Journal of clinical oncology, 20, 3445-3453. http://dx.doi.org/10.1200/JCO.2002.07.500

[8] Meyers, C.A., Smith, J.A., Bezjak, A., Mehta, M.P., Liebmann, J., Illidge, T. and Renschler, M.F. (2004) Neurocognitive Function and Progression in Patients with Brain Metastases Treated with Whole-Brain Radiation and Motexafin Gadolinium: Results of a Randomized Phase III Trial. Journal of Clinical Oncology, 22, 157-165. http://dx.doi.org/10.1200/JCO.2004.05.128

[9] Spreen, O. and Strauss, E. (1998) A Compendium of Neuropsychological Tests: Administration, Norms and Commentary. 2nd Edition, Oxford University Press, New York.

[10] Kurita, G.P., Santos, J. and Pimenta, C.A.M. (2011) Cognitive Assessment of Cancer Patient in Palliative Care: A Systematic Review. Abstracts Book 12th Congress of the European Association for Palliative Care, EAPC, Lisbon, 19-21 May 2011, 159-159.

[11] Arbuthnott, K. and Frank, J. (2000) Trail Making Test, Part B as a Measure of Executive Control: Validation Using a Set-Switching Paradigm. Journal of clinical and experimental neuropsychology, 22, 518-528. http://dx.doi.org/10.1076/1380-3395(200008)22:4;1-0;FT518

[12] Cangoz, B., Karakoc, E. and Selekler, K. (2009) Trail Making Test: Normative Data for Turkish Elderly Population by Age, Sex and Education. Journal of the Neurological Sciences, 283, 73-78. http://dx.doi.org/10.1016/j.jns.2009.02.313

[13] Giovagnoli, A.R, Del Pesce, M., Mascheroni, S., Simoncelli, M., Laiacona, M. and Capitani, E. (1996) Trail Making Test: Normative Values from 287 Normal Adult Controls. Italian journal of neurological sciences, 17, 305-309. http://dx.doi.org/10.1007/BF01997792

[14] Lezak, M., Howieson, D.B. and Loring, D.W. (2004) Neuropsychological Assessment. 4th Edition, Oxford University Press, New York.

[15] Kurita, G.P. and Pimenta, C.A.M. (2008)Cognitive Impairment in Cancer Pain Patients Receiving Opioids: A Pilot Study. Cancer Nursing, 31, 49-57. http://dx.doi.org/10.1097/01.NCC.0000305673.06211.cd

[16] Li, J., Bentzen, S.M., Li, J.L., Renschler, M. and Mehta, M.P. (2008) Relationship between Neurocognitive Function and Quality of Life after Whole-Brain Radiotherapy in Patients with Brain Metastasis. International Journal of Radiation Oncology, Biology, Physics, 71, 64-70. http://dx.doi.org/10.1016/j.jjrobp.2007.09.059

[17] Karnofsky, D.A. and Burchenal, J.H. (1949) The Clinical Evaluation of Chemotherapeutic Agents in Cancer. In: MacLeod, C.M., Ed., Evaluation of Chemotherapeutic Agents, Columbia University Press, New York, 196-196.

[18] Williamson, A. and Hoggart, B. (2005) Pain: A Review of Three Commonly Used Pain Rating Scales. Journal of Clinical Nursing, 14, 798-804. http://dx.doi.org/10.1111/j.1365-2702.2005.01121.x

[19] Mota, D.D.C.F., Pimenta, C.A.M. and Fitch, M.I. (2009) Fatigue Pictogram: An Option for Assessing Fatigue Severity and Impact. Revista da Escola de Enfermagem da USP, 43, 1080-1087.

[20] Ble, A., Volpato, S., Zuliani, G., Guralnik, J.M., Bandinelli, S., Lauretani, F., Bartali, B., Maraldi, C., Fellin, R. and Ferrucci, L. (2005) Executive Function Correlates with Walking Speed in Older Persons: The InCHIANTI Study. Journal of the American Geriatrics Society, 53, 410-415. http://dx.doi.org/10.1111/j.1532-5415.2005.53157.x

[21] Reitan Neuropsychological Laboratory (2012) http://www.mcssl.com/store/reitan-neuropsychology-laboratory/tests/trail-making-test-for-adults-item-18

[22] Botega, N.J., Bio, M.R., Zomignani, M.A., Garcia Jr., C. and Pereira, W.A.B. (1995) Transtornos do humor em enfermaria de clínica médica e validação de escala de medida (HAD) de ansiedade e depressão. Revista de Saúde Pública, 29, 355-363. http://dx.doi.org/10.1590/S0034-89101995000500004

[23] Bjelland, I., Dahl, A.A., Haug, T.T. and Neckelmann, D. (2002) The Validity of The Hospital Anxiety and Depression Scale: An Updated Literature Review. Journal of Psychosomatic Research, 52, 69-77. http://dx.doi.org/10.1016/S0022-3999(01)00296-3

[24] Brucki, S.M., Nitrini, R., Caramelli, P., Bertolucci, P.H. and Okamoto, I.H. (2003) Suggestions for Utilization of the Mini-Mental State Examination in Brazil. Sugestões para o uso do mini-exame do estado mental no Brasil. Arquivos de Neuro-Psiquiatria, 61, 777-781. http://dx.doi.org/10.1590/S0004-282X2003000500014

[25] Tombaugh, T.N. (2004) Trail Making Test A and B: Normative Data Stratified by Age and Education. Archives of Clinical Neuropsychology, 19, 203-214. http://dx.doi.org/10.1016/S0887-6177(03)00039-8

[26] Hirota, C., Watanabe, M., Sun, W., Tanimoto, Y., Kono, R., Takasaki, K. and Kono, K. (2010) Association between 
the Trail Making Test and Physical Performance in Elderly Japanese. Geriatrics \& Gerontology International, 10, 4047. http://dx.doi.org/10.1111/j.1447-0594.2009.00557.x

[27] Kuo, T.T. and Ma, F.C. (2002) Symptom Distresses and Coping Strategies in Patients with Non-Small Cell Lung Cancer. Cancer Nursing, 25, 309-317. http://dx.doi.org/10.1097/00002820-200208000-00007

[28] Davidson, J.R., MacLean, A.W., Brundage, M.D. and Schulze, K. (2002) Sleep Disturbance in Cancer Patients. Social Science \& Medicine, 54, 1309-1321. http://dx.doi.org/10.1016/S0277-9536(01)00043-0

[29] Spoletini, I., Caltagirone, C., Ceci, M., Gianni, W. and Spalletta, G. (2010) Management of Pain in Cancer Patients with Depression and Cognitive Deterioration. Surgical Oncology, 19, 160-166. http://dx.doi.org/10.1016/j.suronc.2009.11.006

[30] Moriarty, O., McGuire, B.E. and Finn, D.P. (2011) The Effect of Pain on Cognitive Function: A Review of Clinical and Preclinical Research. Progress in Neurobiology, 93, 385-404. http://dx.doi.org/10.1016/j.pneurobio.2011.01.002

[31] Ruffolo, L.F., Guilmette, T.J. and Willis, G.W. (2000) FORUM Comparison of Time and Error Rates on the Trail Making Test among Patients with Head Injuries, Experimental Malingerers, Patients with Suspect Effort on Testing, and Normal Controls. The Clinical Neuropsychologist, 14, 223-230. http://dx.doi.org/10.1076/1385-4046(200005)14:2;1-Z;FT223

[32] Mahurin, R.K., Velligan, D.I., Hazleton, B., Mark Davis, J., Eckert, S. and Miller, A.L. (2006) Trail Making Test Errors and Executive Function in Schizophrenia and Depression. The Clinical Neuropsychologist, 20, 271-288. http://dx.doi.org/10.1080/13854040590947498

[33] Ashendorf, L., Jefferson, A.L. and O’Connor, M.K. (2008) Trail Making Test Errors in Normal Aging, Mild Cognitive Impairment, and Dementia. Archives of Clinical Neuropsychology, 23, 129-137. 
Scientific Research Publishing (SCIRP) is one of the largest Open Access journal publishers. It is currently publishing more than 200 open access, online, peer-reviewed journals covering a wide range of academic disciplines. SCIRP serves the worldwide academic communities and contributes to the progress and application of science with its publication.

Other selected journals from SCIRP are listed as below. Submit your manuscript to us via either submit@scirp.org or Online Submission Portal.
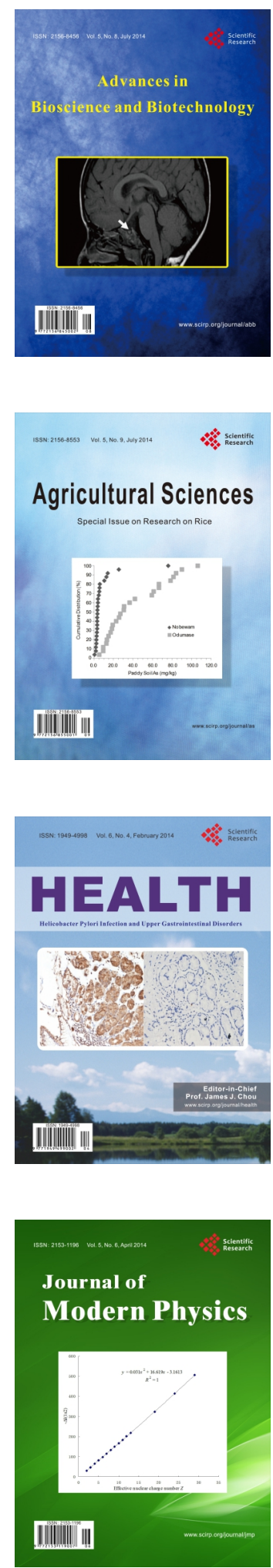
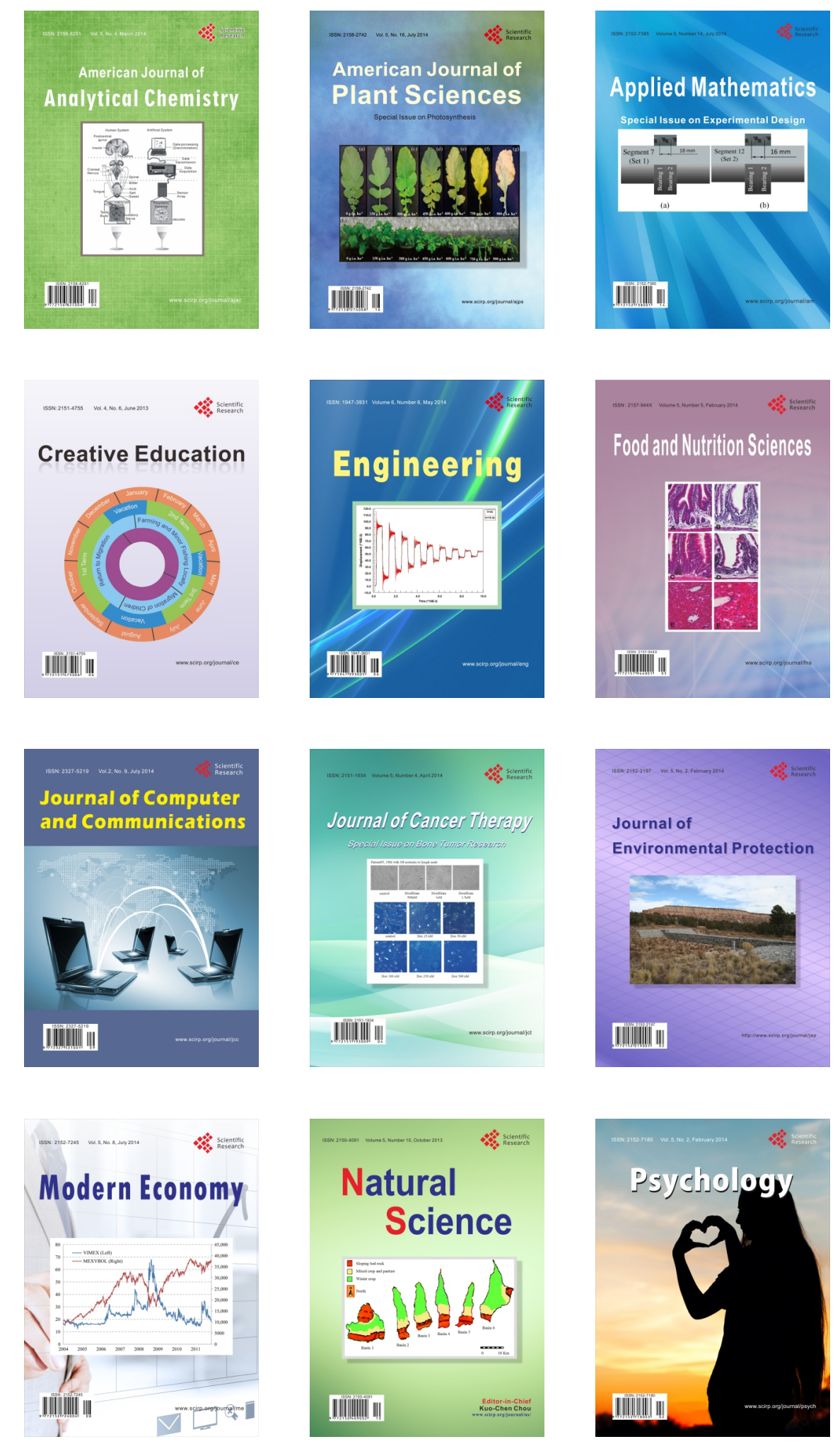